\title{
Skill Levels on Visualization and Spatial Reasoning in Pre-service Primary Teachers
}

\author{
Teresa F. Blanco' ${ }^{1}$, Juan D. Godino², Pablo G. Sequeiros ${ }^{3}$, Jose Manuel Diego-Mantecón ${ }^{4, *}$ \\ ${ }^{1}$ Department of Applied Didactics, Faculty of Education Sciences, University of Santiago de Compostela, Spain \\ ${ }^{2}$ Department of Mathematics Teaching, Faculty of Education Sciences, University of Granada, Spain \\ ${ }^{3}$ Department of Applied Didactics, Faculty of Teacher Training, University of Santiago de Compostela, Spain \\ ${ }^{4}$ Department of Mathematics, Statistics and Computing, Faculty of Sciences, University of Cantabria, Spain
}

Received September 11, 2019; Revised October 29, 2019; Accepted November 8, 2019

Copyright $\mathrm{C} 2019$ by authors, all rights reserved. Authors agree that this article remains permanently open access under the terms of the Creative Commons Attribution License 4.0 International License

\begin{abstract}
We apply theoretical tools from the onto-semiotic approach to present skill levels on tasks requiring visualization and spatial reasoning. These scales are derived from the analysis of visualization and spatial reasoning skills involved in solving a questionnaire supplied to 400 pre-service primary teachers. In order to set skill levels, we describe different types of cognitive configurations considering the network of mathematical objects involved in solving the items. The results show that there may be several configurations at each level and the levels depend on both certain conditions of the task and the visualization skills required. In most cases, the ratio of students expressing high level is significantly below than those of exhibiting low level. The analysis manifests that students put into play variety and quantity of visual objects and processes; however, most did not reach the solution successfully. This leads to the need for specific training actions.
\end{abstract}

Keywords Visualization and Spatial Reasoning, Mathematics Education, Onto-Semiotic Approach, Pre-service Teachers

\section{Introduction}

According to Cunningham (1991) the reinstatement of the visual and intuitive side to mathematics, started decades ago, opens up new opportunities for mathematical work. This leads us to think that the teaching of visualization involves learning new pedagogical skills and that we must not only understand mathematics but also learn to communicate our mathematics visually. Duval (1999) suggests that representation and visualization are situated at the core of comprehension in mathematics; so it is important to analyze to what extent these two elements interact to produce learning. As opposed to other fields of knowledge, the use of semiotic representations is essential in accessing mathematical objects. However, it must be considered that comprehension of mathematics requires distinguishing an object from its representation (Parzysz, 1998; Pittalis \& Christou, 2010).

The relationship between mathematical gift and visualization is receiving a growing interest again; see for example Benedicto, Acosta, Gutiérrez, Hoyos, and Jaime (2015) Ramírez and Flores (2017), and Yenilmez and Kakmaci (2015). In the field of Mathematics Education, the works by Battista (2007), Blanco (2013), Clements (2014), Gutiérrez (1996, 1998), Mix and Battista (2018), Nemirovsky and Noble (1997), Phillips, Norris, and Macnab (2010), Presmeg (2006, 2008), and Rivera (2011) provide us with a tour of the state of affairs in visualization research.

From a more interdisciplinary point of view, spatial ability has been shown to correlate with academic performance in multiple areas -including other domains in mathematics, as has been said- and postulated as one of the most important cognitive abilities in STEM education (Lubinski, 2010; Rafi, Anuar, Samad, Hayati, \& Mahadzir, 2005; Verdine, Golinkoff, Hirsh-Pasek, \& Newcombe, 2014). However, a deeper understanding of how students use this ability in practice is still necessary (Buckley, Seery, \& Canty, 2019).

Our particular interest lies in research related to teacher training in visualization and spatial reasoning (VSR), specifically in pre-service teachers. Several studies have addressed problems of this group as representation of three-dimensional objects (Gaulin, 1985; Malara, 1998), acquisition of basic concepts of geometry (Hershkowitz, 1989; Tatsis \& Moutsios-Rentzos, 2013), concept of symmetry (Son, 2006), identification and classification of 
solids (Guillén, 2005), development of three-dimensional solids (Cohen, 2003), or problem-solving strategies in relation to levels of spatial ability (Buckley, Seery, \& Canty, 2019). Other studies have focused on the mathematical specialized knowledge (Hill, Ball, \& Schilling, 2008) on the specific content of visualization (Godino, Gonzato, Contreras, Estepa, \& Díaz-Batanero, 2016; Gonzato, 2014; Miragliotta \& Baccaglini-Frank, 2017).

In this last direction, the present study focuses on assessing the VSR skills of pre-service teachers with the aim to present, in an exploratory way, skill levels on tasks requiring VSR. Our purpose is to advance in the line of developing theoretical trajectories which may allow us improvement instructional strategies to qualify them to promote VRS skills in primary education pupils. So, a preliminary objective is determining the types of configurations of objects and processes that come into play when future teachers solve VSR tasks. Aforementioned works (Godino, Gonzato, Contreras, Estepa, \& Díaz-Batanero, 2016; Gonzato, 2014) suggest the hypothesis of a variety of configurations from students, which can be described in VSR skill levels. A second hypothesis envisages that the percentage of students who show high-level configurations in relation to the VSR skill is significantly lower than those with low-level configurations.

\section{Theoretical Framework}

The educational aim of our research has led us to adopt the Onto-semiotic Approach (OSA) of mathematical knowledge and instruction (Godino, Batanero, \& Font, 2007; Godino, Font, Wilhelmi, \& Lurduy, 2011) as the theoretical framework to address the design of an instrument to evaluate and analyze the answers provided by the future teachers. The OSA focuses on the analysis of mathematical activity on the practices carried out by people involved in solving certain mathematical task, this being the basic context in which individuals gain their experience and in which mathematical objects emerge (Font, Godino, $\&$ Gallardo, 2013). It is proposed to analyze the types of primary objects involved in a practice, which will be considered as visual if they put the visualization into play. The means of linguistic expression are considered not only as primary objects, but also the concepts, propositions, procedures, properties and arguments. The situations/problems or mathematical tasks from whose solution the previous objects emerge are also considered as objects intervening in the mathematical practice, which must also be visualized. They can be seen the types of visual objects for each of the object categories in Godino, Cajaraville, Blanco, and Gonzato (2012). These six types of primary objects extend the traditional distinction between conceptual and procedural entities by considering them insufficient to describe the objects that intervene in and emerge from mathematical activity. The networks formed by such primary objects and the relationships among them constitute configurations by which the systems of practices are described (figure 1). In this way the situations/problems are the origin or raison d'être of the mathematical activity, the language represents the remaining entities and serves as a tool for action, and the arguments justify the procedures and propositions which relate the concepts among one another (Font, Godino, \& Gallardo, 2013). When the answers provided by individual subjects are analyzed, such configurations are considered to be cognitive, whereas if they are the expected answers from an institutional viewpoint, they are referred to as epistemic configurations.

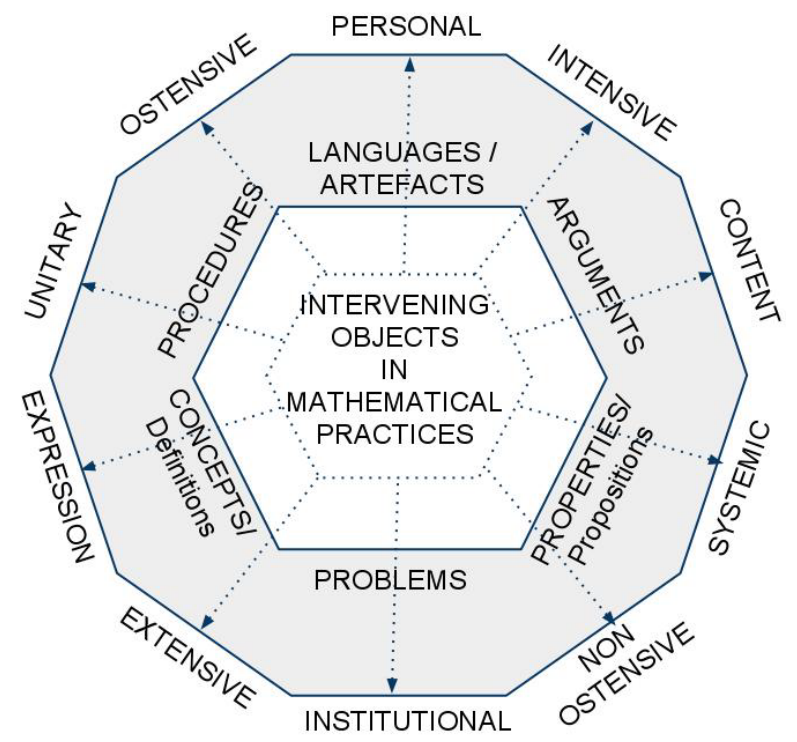

Figure 1. Ontology for an educational mathematics philosophy [Font, Godino, \& Gallardo, 2013, p.117]

On the other hand, the configuration of objects and processes associated with a mathematical practice will usually consist of two components, one visual and the other analytic, which synergistically cooperate on the solution of the corresponding task (Godino, Blanco, Gonzato, Wilhelmi, 2013). The visual component can play a key role in understanding the nature of the task and at the time of making conjectures, while the analytical component will be in the moment of generalization and justification of solutions. The degree of visualization used in solving a task depends on the visual or non-visual character of the task and also on the subject's particular cognitive styles that resolved the task, as has been emphasized by several studies (Godino, Blanco, Gonzato, Wilhelmi, 2013; Krutetskii, 1976; Pitta-Pantazi \& Christou, 2009; Presmeg, 1986; Rabab'h \& Veloo, 2015).

We consider that VSR from this theoretical framework may complement the contributions made from other theoretical perspectives in the field of visualization (Godino et al., 2012) bringing forward a complementary 
viewpoint to address issues such as:

- What kind of different knowledge is at play when performing visualization and spatial reasoning tasks?

- Why do some tasks requiring visualization and spatial reasoning entail a great difficulty for certain students?

\section{Methods}

This study has a strong qualitative component that arises from the in-depth analysis of prototypical examples of student responses to each task, which allows characterizing types of Cognitive Configurations (CC) considering the primary objects of OSA. The analysis of the types of errors that students made to respond to each item also emphasized the qualitative aspect of the study. The incidence in the student sample of the types of cognitive configurations and types of errors is also analyzed from a quantitative point of view, using descriptive statistical techniques.

The population of this study is composed of teacher training students at the University of Santiago de Compostela. The sample comprises 400 students and was collected in a period of three consecutive academic years. The data collection procedure consisted of the implementation of a test, in combination with semi-structured interviews for those cases in which the test answer was vague, incomplete or ambiguous.

The test was designed to analyze different aspects related to spatial skills and capabilities, following the classification of tasks according to the main action required for resolution (Gonzato, Blanco, \& Godino, 2011). In this case, all tasks are performed in the absence of the physical object, so the characteristic of 'initial stimulus' contemplated in that classification is not relevant and the action performed will always be mental. On the other hand, the characteristic of kind of answer required in the realization of the task -identification or construction of an image- has been incorporated from Cosío (1997). Table 1 shows this classification applied to the five tasks that make up our questionnaire, described in the next section.

Table 1. Classification of the tasks in the questionnaire

\begin{tabular}{|c|c|c|}
\hline Item & Action (execute/imagine) & Kind of answer \\
\hline 1 & Counting elements (truncation structure) & Identifying \\
\hline 2 & Composing and decomposing into parts & Identifying \\
\hline 3 & Folding and unfolding & Identifying \\
\hline 4 & Counting elements (area) & Identifying \\
\hline 5 & Rotating & Drawing \\
\hline
\end{tabular}

On the other hand, the tasks belong to the curricular objectives, as the mathematical content in such tasks is considered explicitly or implicitly in the teacher-training curriculum. However, the items included in the questionnaire were selected in such a way that none of them had the same nature as the activities worked in the classroom, in order not to distort the aim of the test, in the sense that the answers should not depend on the kind of previous instruction at the Faculty. Students responded to the questionnaire as a complementary activity to develop in math class, being required to describe the strategy or procedure that led to their answers. The only resources used by the students to develop their responses were pencil and paper.

In order to validate the test, a previous version had been administered to 44 students and had been discussed with a group of experts (Blanco, 2012). The analysis of the visualization processes involved in each task has been carried out by applying the first level of objects of the onto-semiotic configuration (languages, concepts, procedures, properties, arguments), both to the expert reference solution (epistemic configuration) and the solutions given by the students (cognitive configurations) although for reasons of space the epistemic configuration will not be presented, nor will the primary objects be detailed in either case. This analysis, together with the mistakes and difficulties found, enables us to build connections between the different configurations in each one of the items and to establish relationships with previous research. For every item, the effectiveness of each of the associated configurations is also analyzed. The idea of effectiveness (the percent of correct students' answers using that particular configuration) is taken from Gorgorió (1998) and was adapted so that it is relevant only for those configurations susceptible of producing correct results (a valid configuration to achieve the expected result).

Finally, according to the variety of cognitive configurations drawn from the student's answers, we have described skill levels associated to the tasks (Blanco, Sequeiros, Núñez, \& Salgado, 2017). Let's emphasize that the cognitive concept of skill has been interpreted under the terms of the theoretical concepts of the OSA as a system of operational and discursive practices that an individual carries out to solve a certain kind of situations-problems and the configuration of objects and processes connected to such practices. So, such levels will find support in the VSR components at play in each item, through considering the specific component proper to each one of the configurations. At each level there may be several configurations, and in each configuration the visualization skills (Del Grande, 1987) involved may have a different weight.

\section{Results}

This section presents each one of the seven items that make up the questionnaire and includes a schematic description of the different cognitive configurations detected for each item. Respective frequency, percentage and effectiveness are shown in tables 2-6. In addition, a scale of skills with the configurations associated to each level is presented. A more detailed description of these configurations for some items can be seen in (Blanco, 
Diego-Mantecón, \& Sequeiros, 2018, 2019; Blanco, Godino, \& Cajaraville, 2012).

Table 2. Frequency, percentage and effectiveness of the CCs in item 1

\begin{tabular}{|c|c|c|c|}
\hline $\mathrm{CC} 1$ & Frequency & $\%$ & Effectiveness \\
\hline $\mathrm{CC} 1.1$ & 104 & 26.00 & \\
\hline $\mathrm{CC} 1.2$ & 47 & 11.75 & \\
\hline $\mathrm{CC} 1.3$ & 40 & 10.00 & 82.50 \\
\hline $\mathrm{CC} 1.4$ & 29 & 7.25 & \\
\hline $\mathrm{CC} 1.5$ & 24 & 6.00 & 62.07 \\
\hline $\mathrm{CC} 1.6$ & 10 & 2.50 & 60.00 \\
\hline $\mathrm{CC} 1.7$ & 7 & 1.75 & 85.71 \\
\hline $\mathrm{CC} 1.8$ & 6 & 1.50 & 50.00 \\
\hline No Answer & 114 & 33.50 & \\
\hline Total & 400 & 100.00 & \\
\hline
\end{tabular}

Table 3. Frequency, percentage and effectiveness of the CCs in item 2

\begin{tabular}{|c|c|c|c|}
\hline $\mathrm{CC} 2$ & Frequency & $\%$ & Effectiveness \\
\hline $\mathrm{CC} 2.1$ & 64 & 16 & 84.38 \\
\hline $\mathrm{CC} 2.2$ & 65 & 16.25 & 9.23 \\
\hline $\mathrm{CC} 2.3$ & 30 & 7.5 & 80.00 \\
\hline $\mathrm{CC} 2.4$ & 21 & 5.25 & 100.00 \\
\hline $\mathrm{CC} 2.5$ & 13 & 3.25 & 84.62 \\
\hline $\mathrm{CC} 2.6$ & 11 & 2.75 & 90.91 \\
\hline $\mathrm{CC} 2.7$ & 11 & 2.75 & 100.00 \\
\hline $\mathrm{CC} 2.8$ & 17 & 4.25 & 70.59 \\
\hline No Answer & 168 & 42 & \\
\hline Total & 400 & 00 & \\
\hline
\end{tabular}

Table 4. Frequency, percentage and effectiveness of the CCs in item 3

\begin{tabular}{|c|c|c|c|}
\hline $\mathrm{CC} 3$ & Frequency & $\%$ & Effectiveness \\
\hline $\mathrm{CC} 3.1$ & 210 & 52.50 & 89.05 \\
\hline $\mathrm{CC} 3.2$ & 52 & 13.00 & 88.24 \\
\hline $\mathrm{CC} 3.3$ & 23 & 5.75 & 100.00 \\
\hline $\mathrm{CC} 3.4$ & 11 & 2.75 & 100.00 \\
\hline $\mathrm{CC} 3.5$ & 4 & 1 & 100.00 \\
\hline No Answer & 100 & 25 & \\
\hline Total & 400 & 100 & \\
\hline
\end{tabular}

Table 5. Frequency, percentage and effectiveness of the CCs in item 4

\begin{tabular}{|c|c|c|c|}
\hline CC4 & Frequency & $\%$ & Effectiveness \\
\hline CC4.1 & 70 & 17.50 & 74.29 \\
\hline CC4.2 & 81 & 20.25 & 86.42 \\
\hline CC4.3 & 30 & 7.50 & \\
\hline CC4.4 & 14 & 3.50 & 28.57 \\
\hline CC4.5 & 12 & 3.00 & 100.00 \\
\hline CC4.6 & 8 & 2.00 & \\
\hline CC4.7 & 10 & 2.50 & \\
\hline CC4.8 & 8 & 2.00 & \\
\hline CC4.9 & 84 & 21.00 & \\
\hline No Answer & 83 & 20.75 & \\
\hline TOTAL & 400 & 100 & \\
\hline
\end{tabular}

Table 6. Frequency, percentage and effectiveness of the CCs in item 5

\begin{tabular}{|c|c|c|c|}
\hline CC5 & Frequency & $\%$ & Effectiveness \\
\hline CC5.1 & 196 & 49.00 & \\
\hline CC5.2 & 66 & 16.50 & 3.03 \\
\hline CC5.3 & 21 & 5.25 & 38.10 \\
\hline CC5.4 & 23 & 5.75 & \\
\hline CC5.5 & 17 & 4.25 & 0.00 \\
\hline CC5.6 & 21 & 5.25 & 0.00 \\
\hline CC5.7 & 9 & 2.25 & \\
\hline CC5.8 & 10 & 2.50 & 10.00 \\
\hline CC5.9 & 5 & 1.25 & 80.00 \\
\hline No Answer & 32 & 8.00 & \\
\hline Total & 400 & 100.00 & \\
\hline
\end{tabular}

\section{Cognitive Configurations in Item 1}

Item 1. All the corners of a cube of size $2 \mathrm{~cm}$ are cut as indicated in the figure, at a distance of $1 \mathrm{~cm}$ from each vertex on each edge. How many vertices does the new solid have? a) 6 b) 8 c) 12 d) 18 e) 24

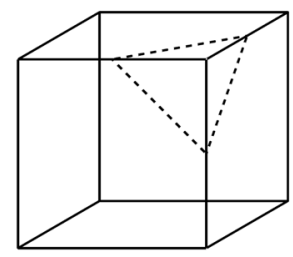

Figure item 1

CC1.1 Truncating a vertex in the cube leads to three vertices in the new solid which are multiplied by the number of vertices of the initial cube. This configuration is associated to the mistake of not considering that each vertex of the cuboctahedron is common to two triangular faces.

CC1.2 Identifying the resulting solid with a cube/cuboid. The original cube is cut by four planes perpendicular to a face, passing in each case through the midpoints of two edges sharing a vertex. Each one of the four planes cuts the edges of the initial cube at four points (two in adjacent edges of one face and another two in the homologous edges of the opposite face).

CC1.3 Exhaustive verification of cases in a finite number. It is based on the graphic representation of the midpoints of the edges, marking on each edge of the cube the new vertices and counting their total number. This procedure involves in most cases accompanying a graphic representation (sketch) of the new solid.

CC1.4 Multiplying the number of vertices in a quadrangular face of the new solid by the number of faces of the cube. These elements are considered to be independent from one another, 
which leads to not considering that every two quadrangular faces share a vertex.

CC1.5 Identifying the number of cut-off points on the edges of the initial cube with the number of vertices of the new solid. Attention is focused on the edges of the initial cube, isolating the remainder of elements. Each edge of the cube provides one vertex of the truncated cube (or 2 vertices, when students apply the strategy wrongly).

CC1.6 Extrapolating the action on a vertex of the cube with integration. This configuration is based on extrapolating what happens to one of the cube vertices to all the others, considering afterwards the points in common to adjacent faces.

CC1.7 Extrapolating the action on a face of the cube with integration. In this case, based on extrapolating what happens to one of the faces to all the others, considering afterwards the points in common to adjacent faces.

CC1.8 Exhaustive verification of cases, based on a net arrangement of the cube. The net arrangement of the cube is displayed out marking on each face of the net the polygon resulting from cutting the four vertices of such face.

VSR Skill Levels in Item 1

Level 1 is based on the visual characteristics that focus partially on what happens to one of the faces. The image that appears takes us to the prototypical image of the face of a cube (cuboid) seen from any of its orthogonal propositions. Spatial relationships skill, which allows to establish the relationship between the inclination of the cutting plane and the edges of the truncated cube, does not come into play. Only CC1.2 corresponds to this level.

At level 2 (CC1.1 and CC1.4), what happens to the vertices (faces) is extrapolated to the remainder of elements of the cube (vertices or faces), whereby a relationship is established between the action on one of the elements of the cube and the remainder of elements of the same kind. However, there is no integration of the effect produced by such action on two contiguous elements (vertices or faces). The spatial structure of the figure is based on a set of faces that are not coordinated.

Level 3 (CC1.3 and $\mathrm{CC} 1.8)$ requires the visual identification of the elements (vertices) of the new figure, isolating them from the elements of the initial cube. They ostensibly perform all the action, which provides them, in the case of configuration $\mathrm{CC} 1.3$, with an image of the resulting solid.

At level 4 (CC1.5, CC1.6 and CC1.7), there is a total integration of the cube structure and the performed action. In configuration $\mathrm{CC} 1.5$ a two-way relationship is established: each cutting point on one of the cube edges leads to a vertex of the new solid. In CC1.6 and CC1.7 the action is performed on one kind of element of the cube (vertex, face, edge), though considering the spatial relationships that are established when performing the cuts and extrapolating to the remainder of elements.

\section{Cognitive configurations in item 2}

Item 2. A rectangular parallelepiped is formed using 4 pieces, each one made up of 4 cubes (see figure). Three of the pieces are fully visible; the dotted one is only partially visible. Which one of the following 5 pieces is the dotted one?
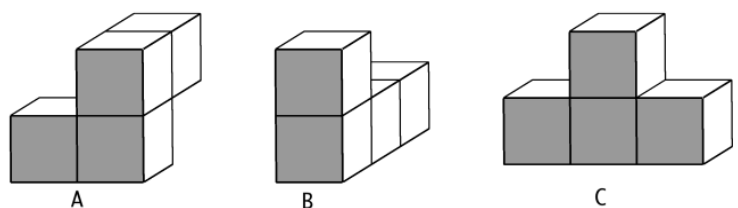

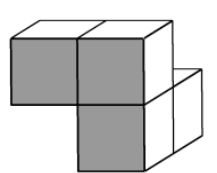

D

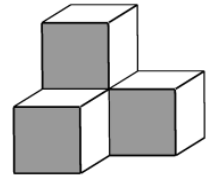

E

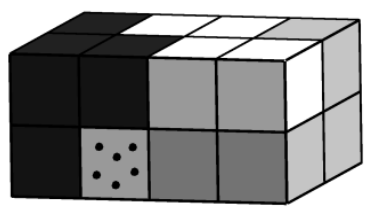

Figure item 2 
CC2.1 Deductive justification for the dotted piece. The shape of the dotted piece is deduced by considering the space occupied by the other pieces and comparing the remaining space with the possible solutions.

CC2.2 Visual discrimination. A visual scan is performed to see how the parallelepiped is formed and what the pieces are like, after which some of the pieces may be discarded, as they are not a valid option for the dotted piece being sought.

CC2.3 Exhaustive verification by fitting the pieces. Attempting to fit in turn each piece provided as possible solutions to the task.

CC2.4 Decomposition by means of topographical level sections. The cuboid is separated into two levels by means of a horizontal plane and the position occupied by the smaller cubes in each level is observed. It consists of suppressing the upper level and visualizing or drawing the remainder of pieces on the lower one.

CC2.5 Representation by means of orthographic projection. Drawing the different views (above, below, front, back, right and left) of the parallelepiped by means of its orthogonal projections onto the plane.

CC2.6 Successive suppression of the visible pieces in the solid. The visible pieces that make up the parallelepiped are suppressed one by one, in order to leave only the smaller cubes belonging to the dotted piece.

CC2.7 Assigning numbers to each one of the cubes that make up the parallelepiped. A number from 1 to 16 is assigned to each one of the cubes in the parallelepiped to better recognize the spaces occupied by the non-visible cubes of the dotted piece.

CC2.8 Deductive analysis on the shape of the dotted piece. This configuration is based on the deduction of the possible shape of the dotted piece, considering that the second level of the parallelepiped is occupied. This fact leads to two possible options: $\mathrm{B}$ or $\mathrm{C}$.

VSR Skill Levels in Item 2

Level 1: CC2.2. The position occupied by the smaller cubes is not considered. Therefore, the skill regarding the preservation of spatial positions is not developed nor is the skill of mental rotation. It is based on appreciations of a visual kind. Besides, the parallelepiped is not considered as a whole, as only the action on the front face is considered but not the actions on the other faces.
Level 2: CC2.3. Although it does use recognition of the spatial relationships and positions, such recognition is not applied in order to discard some of the pieces but is used to verify exhaustively with each one of them whether they correspond to the dotted piece or not.

Level 3: CC2.8. Recognizing the spatial positions enables to eliminate the entire upper level. Attention is then focused on the pieces that may be positioned in such a way that they only take up one level (recognizing spatial relationships).

Level 4: CC2.4, CC2.5, CC2.6, CC2.7, CC2.1. Configurations $\mathrm{CC} 2.4$ and $\mathrm{CC} 2.5$ require knowledge skills to convert flat representations of three-dimensional objects. In either case, recognizing the positions of the smaller cubes in the different pieces enables to obtain the positions of the smaller cubes of the missing piece. Afterwards, it requires coordinating and integrating them to make up the dotted piece. Configuration CC2.6 requires a constant recognition of the spatial position and relationship of the pieces to the parallelepiped and to the remainder of pieces. Such recognition takes place piece by piece and not smaller cube by smaller cube as in the previous ones. The piece being sought does not need to be deduced because it 'appears'. Configuration CC2.7 establishes a two-way relationship between numbers 1 to 16 corresponding to the smaller cubes that make up the different pieces and the positions occupied by the smaller cubes in a three-dimensional grid. Configuration CC2.1 does not need to establish this relationship because it is done directly.

In any one of the configurations above, recognizing the spatial relationships will enable to deduce that the piece being sought is in another position. Effectiveness in all the configurations of levels 3 and 4 is above $75 \%$, reaching $100 \%$ in configurations $\mathrm{CC} 2.7$ and $\mathrm{CC} 2.4$.

\section{Cognitive Configurations in Item 3}

Item 3. We cut one vertex of a cube. Which one of the following flat developments corresponds to the resulting solid?
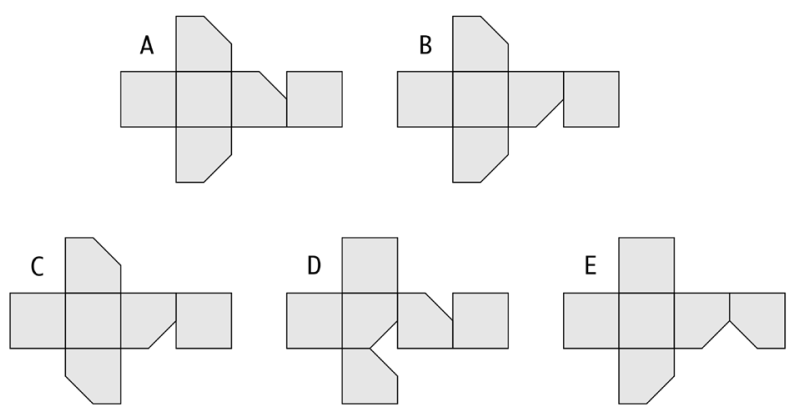

Figure item 3 

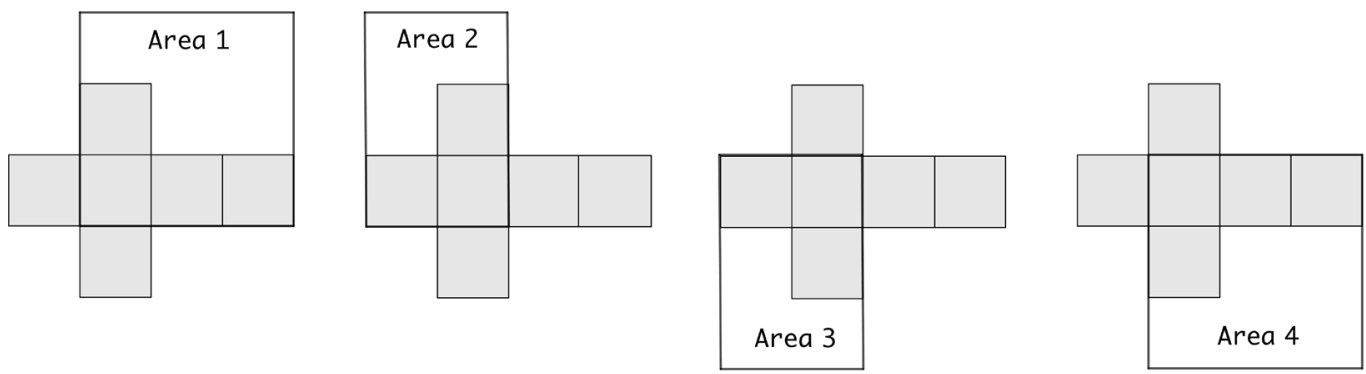

Figure 2. Areas in the net arrangement of the cube

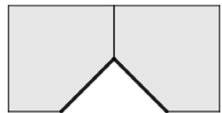

Figure 3. "Triangle"

CC3.1 Exhaustive composition of the cut cube. Exhaustive verification of cases, folding the faces of the net arrangement to recompose the cube with one vertex cut off. It is a mental verification. Some answers show the folded cube with a cut on one of the vertices that is used as a reference as each one of the options is formed mentally.

CC3.2 Drawing a cube with the corner cut off and arranging it in net form. The corner cut off usually appears as the upper front right corner. This may be due to the image provided in item 1, as some students claim. On other occasions they are assisted by a verbal explanation, though every action is developed mentally.

CC3.3 The faces cut off belong to the same 'area'. In this case the student considers that the corners cut off must be situated 'on the same side' (figure 2). This means that this condition becomes necessary when folding the net arrangement to form the cube with a vertex cut off.

CC3.4 Visual recognition of a (imagined) triangle. It is based on discarding the net arrangements that do not represent the situation in which two cut faces (pentagons) are contiguous in the net arrangement, sharing one of the cut edges in some position of the arrangement (figure 3). This situation is considered a necessary condition for the answer to be correct.

CC3.5 Setting one of the bases of the cube as the cut face. It is discriminated according to whether the square that acts as the top (upper base) of the cube is cut or not. This configuration entails considering that the cut must be made on one of the upper corners. In this case, the preservation of perception skill is not totally developed, as the shape is maintained even though it may have been turned and the vertex cut off is in another position.

\section{VSR Skill Levels in Item 3}

Level 1: CC3.1. There is no kind of discrimination of the net arrangements presented. The visual discrimination skill enables to compare the mental image of a cube with a vertex cut off (visual memory skill) to the mental images that are obtained as the different net arrangements are assembled.

Level 2: CC3.2 and CC3.5. The conceptual images created are deficient when certain conceptual or visual constraints are required. Therefore, subjects only accept those images that coincide with the prototypical ones that they have.

Level 3: CC3.3 and CC3.4. Before applying the visual discrimination skill, certain net arrangements are discarded, as they do not meet certain conceptual or visual properties imposed. Although, we must highlight that these cognitive configurations are not made up of a great variety of examples.

Level 4. Epistemic analysis indicates that a solution at this level corresponds to apply the visual discrimination skill to consider that, as three sides meet at each vertex in a cube, cutting one implies cutting three of their adjacent faces. Those developments where a cut edge is adjacent to a full edge are discarded. Based on this proposition (necessary but not sufficient) all developments except (E) are discarded. The ability to recognize spatial positions allows composing the cube with a truncated vertex. In the analyzed sample no configuration has been found at this level.

It may be observed that the students are not used to working with net arrangements of the cube that are different from the format 1-4-1 (Mesquita, 1992, p.29) and even less with net arrangements of figures other than a cube. Effectiveness was high for all the configurations, reaching 100\% for CC3.3, CC3.4 and CC3.5 despite being based on properties that are neither sufficient nor necessary. 


\section{Cognitive Configurations in Item 4}

Item 4. Some tunnels are pierced into a large cube as per the figure. How many smaller cubes are there? a) 88 b) 80 c) 70 d) 96 e) 85

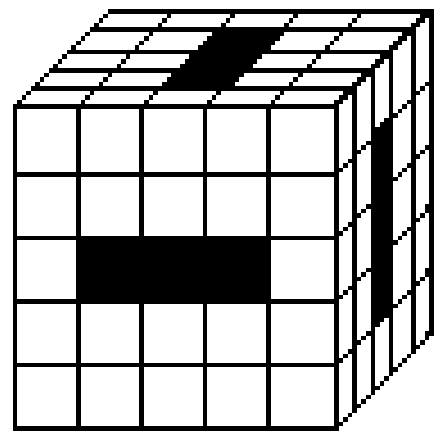

Figure item 4

CC4.1 Using extractive procedures. It is based on the use of the traditional formula to calculate the volume as a product of three dimensions (length $\times$ width $\times$ height). Once the volume of the complete cube is calculated, the measurement of the volume of the tunnels is subtracted.

CC4.2 Volume as an empty space. It is considered that the cube is made up only of its outer layers. So, the calculations are performed considering only the faces. The underlying idea is conceiving volume as the capacity of a container, as an empty space limited by the faces.

CC4.3 Orthogonal decomposition by layers. The perforated cube is decomposed into 5 layers following an orthogonal scheme (horizontal or vertical) by levels, counting the volume units of each layer and adding them up.

CC4.4 Decomposition of the cube into inside-out sections. The figure is decomposed in sections going from outside to inside (or vice-versa) in the form of cuboids $a \times b \times 1,3 \leq a, b \leq 5$.

CC4.5 Translation of tunnels. The tunnels are translated in such a manner that they are all located around a vertex (figure 4). The procedure used may be justified by means of an argument that considers volume as a global whole (subtractive procedure) or in parts (summative procedure).

CC4.6 Extracting the pieces that are complementary to the tunnels. This is a summative procedure on the complement of the tunnels that avoids the complexity of calculating the measurement of the tunnels and their intersections (figure 5). Each type of structure may be counted or otherwise the symmetry of the figure may be to count only a part.

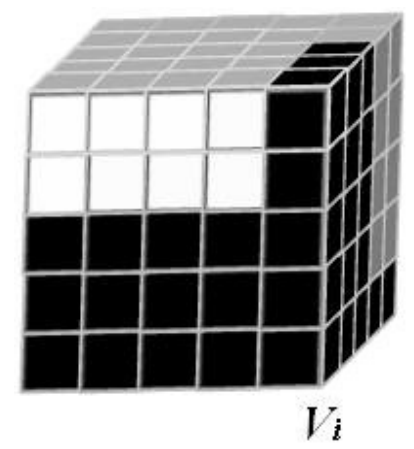

Figure 4. Translation of the tunnels to the vertex $V i$
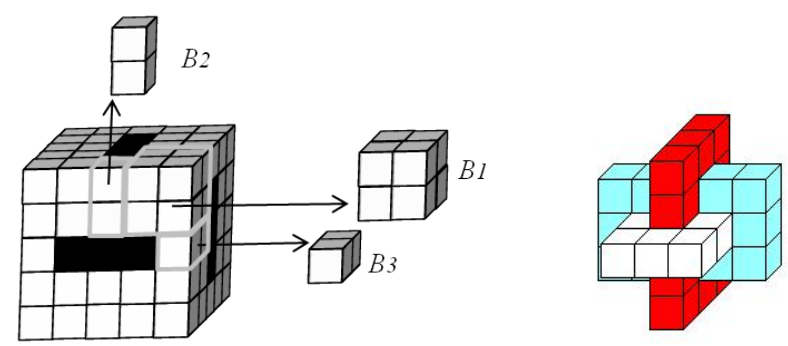

Figure 5. Explanation of the procedure associated to CC4.6

\section{VSR Skill Levels in Item 4}

Level 1: CC4.2. Only the external structure of the 3D arrangement is considered. There is no coordination of the different faces and perspectives. The $3 \mathrm{D}$ arrangement is not considered as a coordinated set of faces.

Level 2: CC4.4 and CC4.5. In configuration CC4.5, the arrangement provided does not enable to create suitable images for counting and a restructuring of the position of the elements of the cube (smaller cubes) must be carried out in order to solve the task. Recognition of the spatial relationships and positions is applied several times, the first one being the moment when all the elements that make up the tunnels are repositioned. In the case of configuration CC4.4 different perspectives must also be coordinated to consider the different plates that are being obtained. Following Battista (2007, p. 898), the mental models created enable to obtain correct answers, though they may not be generalized and are unsuitable for large-scale matrix structures.

Level 3: CC4.3. The skills to recognize spatial positions and relationships are evidenced in order to carry out flat representations of cube modules. Structuring layers or rows by columns enable to locate the units in a precise manner.

Level 4: CC4.1 and CC4.6. In configuration CC4.6, as opposed to the other configurations, the visual identification skill at play enables to isolate the image of the perforated cube from the image of the cube with the tunnels. Recognizing the spatial positions and relationships enables to structure such perforated cube into several pieces that in turn facilitates counting them. In configuration $\mathrm{CC} 4.1$ the visual identification skill is also at play to isolate the tunnel from the complete cube. Besides, different perspectives must be coordinated in order to 
create the mental image of the tunnel intersections.

\section{Cognitive Configurations in Item 5}

Item 5. Draw, as best you can, what bodies would be obtained by rotating the figures with respect to the indicated axes.
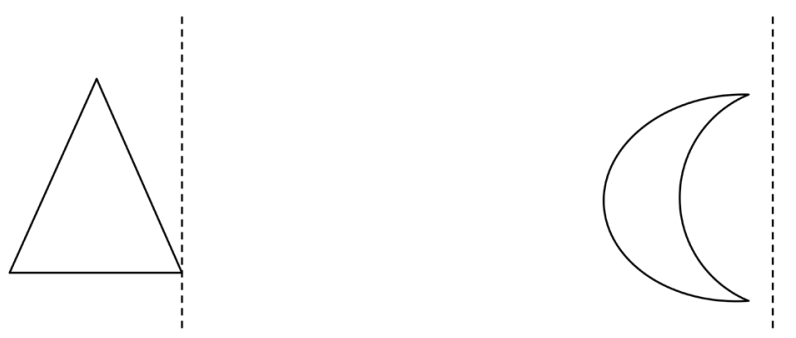

Figure item 5

CC5.1 Interpreting the axis of rotation as an axis of symmetry. In this configuration the created mental images are the symmetrical figures of the given ones. In some cases, these mental images are obtained by a 'turnaround', i.e. pivoting $180^{\circ}$ around the axis and considering only the initial and final situations.

CC5.2 Graphic representation of the resulting bodies without the physical support of the axes provided. In this case the bodies of revolution are represented, though without using the axis to build a symmetry plane of the body.

CC5.3 Marking circumferences to confer a three-dimensional effect. Justification supported on the use of graphic representations, drawing the figures that are symmetrical to the ones provided and the circumferences of the upper and lower parts to provide a three-dimensional effect (sensation of volume).

CC5.4 Free rotations on the plane. Graphic justification by applying a rotation on the plane to each one of the figures around one of their vertices or by simply rotating them without setting the center of the turn. In many cases the main goal is to pass them completely to the other side of the axis. All the turns that are considered necessary for the resolution, with an equal or different amplitude, are applied to the figures.

CC5.5 Absence of graphic representation. The resulting bodies as well as the actions carried out to obtain them are described verbally. There is an attempt to describe the mental action involved without support on graphic (ostensive) representations.

CC5.6 Graphic representation of the orthogonal frontal section. The procedure followed consists in drawing the figures symmetrical to the given ones and then joining them by segments, giving rise to the orthogonal-frontal section of each one of the generated solids of revolution. In one case the planar representation presents a trapezoid formed by three congruent isosceles triangles, in the other one two closed curves that approximate two concentric ellipses.

CC5.7 Graphic justification applying a rotation of $180^{\circ}$ and one translation. It is based on applying to each one of the two figures a composition of movements: central symmetry or $180^{\circ}$ turn and translation.

CC5.8 Creation of a continuum of images. Graphic representation of different views in perspective of the flat figures on the space as they pivot around the axes. It would require coordination and integration of all such images in order to reconstruct the global image of the body generated (figure 6).

CC5.9 Plan and elevation of the resulting bodies. Obtained by drawing the figures symmetrical to the given ones and straight lines parallel to the axis that pass through the vertices of the given figures to determine in each case two concentric circles that represent the plant of the bodies of revolution generated.

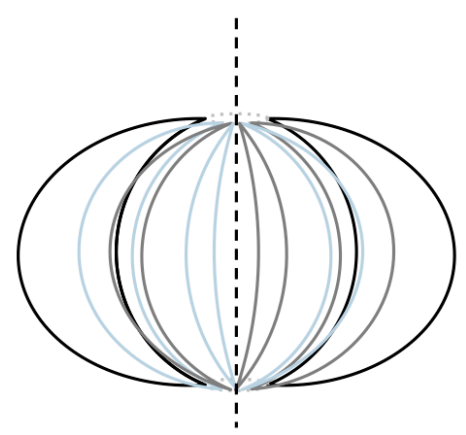

Figure 6. Image describing configuration CC 5.8 


\section{VSR Skill Levels in Item 5}

Level 1: CC5.1, CC5.4 and CC5.7. Attention is focused on visual associations, either with prototypes or verbal associations of one word with its most usual meaning. The skills of preservation of perception and of spatial relationships are applied to the plane and not to the space, and then not always correctly.

Level 2: CC5.5. The skills of mental rotation, recognition of positions in space and preservation of spatial relationships are enacted. However, no conventions of flat representations of three-dimensional objects are used to render a graphic representation of such bodies. The difficulty lies in the graphic communication of the information, though the mental images created may be correct.

Level 3: CC5.2, CC5.6 and CC5.8. The bodies are not provided with full depth and therefore, in most cases, the kind of representation is a mixed one, needing verbal support in order to communicate the complete structure of the body generated. In CC5.6 no conventions are used to represent three-dimensional objects, presented only by one of the orthogonal views. Moreover, in CC5.2 and CC5.8 the conventions are used to draw three-dimensional objects. However, no hollow spaces nor other internal characteristics of the figures are indicated, not providing complete information about the images created.

Level 4: CC5.3 and CC5.9. Recognizing positions in space and preserving spatial relationships skills are evidenced by implementing the conventions used for two-dimensional representations of three-dimensional bodies. The information about the mental images created (mental rotation skill) is communicated clearly enough.

\section{Discussion}

Given the distribution of correct answers per item (table 7 ), with percentages below $40 \%$, except for item 3 , it becomes evident that, except for that case, the tasks requiring VSR submitted are not a part of the usual practice of these students. It has been shown this type of tasks entail a great difficulty for students, which express a number of conflicts when solving them.

Table 7. Analysis of global results $(n=400)$

\begin{tabular}{|c|c|c|}
\hline Item & Correct answers & Percentage \\
\hline 1 & 73 & 18.25 \\
\hline 2 & 154 & 38.50 \\
\hline 3 & 304 & 76.00 \\
\hline 4 & 85 & 21.25 \\
\hline 5 & 16 & 4.00 \\
\hline
\end{tabular}

A variety of configurations have been found for all items, confirming the first hypothesis. For items 1 and 2, eight configurations were categorized, five for item 3 , and nine for items 4 and 5. Frequency, percentage and effectiveness of configurations associated to each item are shown in tables 2 to 6 . For each item, these configurations have been grouped into skill levels, as shown in table 8.

Table 8. CCs and percentage of responses by item and level

\begin{tabular}{|c|c|c|c|c|}
\hline Item & Level 1 & Level 2 & Level 3 & Level 4 \\
\hline \multirow[t]{2}{*}{1} & $\mathrm{CC} 1.2$ & $\mathrm{CC} 1.1, \mathrm{CC} 1.4$ & $\mathrm{CC} 1.3, \mathrm{CC} 1.8$ & $\begin{array}{c}\mathrm{CC} 1.5, \mathrm{CC} 1.6 \\
\mathrm{CC} 1.7\end{array}$ \\
\hline & $11.75 \%$ & $33.25 \%$ & $11.50 \%$ & $10.25 \%$ \\
\hline \multirow[t]{2}{*}{2} & $\mathrm{CC} 2.2$ & $\mathrm{CC} 2.3$ & $\mathrm{CC} 2.8$ & $\begin{array}{c}\mathrm{CC} 2.4, \mathrm{CC} 2.5 \\
\mathrm{CC} 2.6, \mathrm{CC} 2.7 \\
\mathrm{CC} 2.1\end{array}$ \\
\hline & $16.25 \%$ & $7.5 \%$ & $4.25 \%$ & $30 \%$ \\
\hline \multirow{2}{*}{3} & $\mathrm{CC} 3.1$ & $\mathrm{CC} 3.2, \mathrm{CC} 3.5$ & $\mathrm{CC} 3.3, \mathrm{CC} 3.4$ & - \\
\hline & 52.50 & 14 & 8.50 & 0 \\
\hline \multirow{2}{*}{4} & $\mathrm{CC} 4.2$ & $\mathrm{CC} 4.4, \mathrm{CC} 4.5$ & $\mathrm{CC} 4.3$ & $\mathrm{CC} 4.1, \mathrm{CC} 4.6$ \\
\hline & $24.25 \%$ & $0.75 \%$ & $6.75 \%$ & $42.50 \%$ \\
\hline \multirow[t]{2}{*}{5} & $\begin{array}{c}\text { CC5.1, CC5.4 } \\
\text { CC5.7 }\end{array}$ & CC5.5 & $\begin{array}{c}\text { CC5.2, CC5.6 } \\
\text { CC5.8 }\end{array}$ & CC5.3, CC5.9 \\
\hline & $57 \%$ & $4.25 \%$ & $24.25 \%$ & $6.50 \%$ \\
\hline
\end{tabular}


With regards to the second hypothesis, as shown in table 8 , the percentage of high-level configurations detected is rather higher for items 2 and 4, above the percentage for the low-level configurations. However, in general, the second hypothesis -the percentage of students showing high-level configurations in relation to the VSR skills is significantly lower than those with low-level configurations- is confirmed. Next, we discuss the above levels in relation to the kind of knowledge involved when performing the tasks, as well as the conflicts and difficulties detected in the students' answers.

\subsection{Low-level: Levels 1 and 2}

We assign to level 1 those configurations whose procedure would never lead to the correct solution (for example, CC4.2 or CC5.1) or those that would do so by chance, without any discrimination (CC3.1). Also, those based on visual associations with prototypes of figures and procedures (CC5.1). In level 2 configurations, the solution can always be reached, or the procedure fails only in its final part (CC1.1 and $\mathrm{CC} 1.4)$.

The main conflicts detected when analyzing the configurations associated to lower levels are directly related with interpreting the flat representation of a three-dimensional object. This is a fundamental aspect in visualization, as noted in the introduction (see Cohen, 2003; Gaulin, 1985; Malara, 1998). This kind of conflicts can be observed, mainly, in item 2 -as thinking the pieces given as options to must maintain their position in space $(15.25 \%)$ or trying to recognize one of the options given in the parallelepiped just as it is represented in the figure $(0.75 \%)$ - and item 4 -as identifying only one intersection ( $1 \%)$, two intersections $(2.75 \%)$ or identify two-to-two intersections but not that of the three tunnels $(2,25 \%)$.

Regarding low-levels, results show, as in Malara (1998), that future teachers have found difficulties to coordinate the partial views of an object, to visualize objects globally, to evoke the view from one of their four fundamental viewpoints as well as to verify the correctness of their productions and conceptualize the principles of representation. In particular, we can state, as in Battista and Clements (1998, p. 504), that students who have a spatial structure of figures based on a set of uncoordinated faces will perform double counting of elements (vertices, edges, units) that are part of two or more faces, as shown in the analysis of errors of item 1 -do not taking into account that each vertex of the cuboctahedron is common to two triangular faces- and item 4 -duplicating the cube faces appearing in the drawing or assigning four faces to the cube.

It has been observed that such students have very vague and limited ideas about basic concepts such as symmetry, turn, cube, cuboid, etc., and often the meaning they attribute to them is based on prototypical examples. Hence, conflicts appear between the verbal definition of a figure and the image that is presented. For example, in item 5, it is likely that if explicitly requested all students will be able to give a correct definition of the cube (number of faces, edges and vertices). However, when counting the volume units in the perforated cube, a high percentage of students multiplies the number of units of a face by four (identification with a square) or by three (the faces shown in the given flat representation).

Items 1, 3 and 5 are those with the highest incidence of low-level configurations (table 8). In the search for causes, it is observed that the answer requested in item 5 involves the drawing of a figure and, in addition, the concepts involved refer to movements in the plane or the space: axis of rotation/symmetry, fixed points and the properties of axis perpendicularity and perpendicularity between the axis and the segment joining a point with its image. Also, in item 5 the concepts of path, gap and trajectory appears. With respects to items 1 and 3 the connection for the results obtained could reside in the concepts: intersection of planes, truncated solids and polyhedron angles, whose presence is not usual in the instruction received by the subjects participating in the study.

Regarding the action required in the task, item 1 implies counting elements, not on the given figure, but on an unknown one. In order to obtain that other figure, it is necessary to perform another action: cut the vertices. In item 3 , the required action is to fold. In this task, although the figure (cube) and its flat development (standard cross-shaped development) are known, a new element is added since the cube has a cut vertex. In the case of item 5, it is required rotating the given figures to generate solids of revolution. The flat figures in the task are known. However, they are placed at some distance from the axis, a situation less usual in school activities.

As another feature of the task most affecting the solution have been identified the visual references or restrictions. The onto-semiotic analysis has enabled to explain that, when solving most of the tasks, visual references or restrictions are stronger for students than the references provided in a worded sentence. For example, in the case of item $1,33.7 \%$ do not consider that the cut is performed at 2 $\mathrm{cm}$; in item 4, 24.5\% do not consider the fact that the tunnels pierce the cube; and in item 5, 49.5\% of the subjects do not notice the word 'rotating'. Such power of visual over verbal must be channeled, that is, it is necessary to learn to manipulate it in order to be able to work and reason with such images.

\subsection{High-level: Levels 3 and 4}

The highest levels of visualization involve the recognition of positions and relationships in space, implementing the conventions used for two-dimensional representations of three-dimensional bodies, coordinating figures elements and integrating figures structures. The difference between levels 3 and 4 is given above all in the 
fact that in the last level there is a total integration of the figure and the information about the mental images created is communicated clearly enough, see for example CC4.1 or CC5.9. A good resolution strategy is coordinated with the ability to communicate the information necessary to solve the problem, either verbally or graphically.

In fact, difficulties were detected when the students had to reason their solution. A conflict occurs when they try to express verbally or graphically the process by which they reach a concrete solution. According to Gorgorió (1998), in order to solve a spatial task, it is possible to follow a kind of strategy that is not grounded on visual objects and processes. Participants with lower levels of spatial capacity tend to use models allowing them to avoid spatial reasoning (Buckley, Seery, and Canty, 2019). In the analysis performed on the configurations, all the configurations obtained are visual configurations (Godino et al., 2012) and it has been observed, through their cognitive configurations, how the students have mostly used visual arguments when solving the tasks proposed.

In the case of the items with higher percentage of high-level configurations, the required action is, for item 2 , to compose/decompose into parts and, for item 4, to count parts/units of measure of volume, more familiar actions for this type of students. To solve such tasks, they mobilize a variety and quantity of visual objects (visual properties, mental images, etc.). However, this does not mean that the actions on such elements are always performed correctly, as may be proven by analyzing the effectiveness of such configurations.

It has also been observed that many high-level configurations in VSR do not reach $100 \%$ effectiveness, also due to the kind of answers requested. This fact is observed to a greater extent in item 5 , the one with the lowest percentages of correct answers (4\%), for which the required answer is to draw.

In general, important limitations have also been found when students communicate the visual information, for example when they use the words 'circle' (or 'circumference') and they mean to say 'sphere'. As in Saads and Davis (1997), students used a wrong geometric vocabulary to name the faces of three-dimensional figures, using the same term to refer to both the faces and edges of the cube.

\section{Conclusions}

In this study we have applied the notion of cognitive configuration, through the onto-semiotic approach to mathematical knowledge (OSA), to describe and interpret student responses to tasks requiring visualization and spatial reasoning in terms of geometrical objects (representations, concepts, properties, procedures and arguments) which are involved in their resolution, in order to establish a type of scale on VSR. Each of the responses of the 400 students to the 5 tasks of the questionnaire leads to a specific cognitive configuration. However, we have classified the types of responses for each item by comparing the types of geometric objects that are put into play. In this way, the types of cognitive configurations correspond to the types of responses, which are characterized indicating the geometrical objects involved in the resolution. This enables a detailed analysis of the strategies and thinking schemes that the students use to solve the tasks.

The onto-semiotic analysis has allowed associating a diverse set of configurations for each item and has revealed that students mobilize a large number of visual objects and processes. However, they do not do so efficiently and often not even consciously. We have seen in how one of the greatest conflicts or difficulties encountered when solving the tasks has to do with such lack of interrelation between representation and visualization. We have ascertained that the features of the task, essentially the action required, make up one of the elements that most affected its solution. Also, visual references or restrictions are stronger for students than the references provided in a worded sentence.

The variety of configurations associated with each item allowed us to establish four levels of VSR for each item. Our goal is to advance in the difficult purpose of setting up a more general scale of skills in VSR, although we should justify (Godino \& Burgos, 2017) why four levels and not a different number would be proposed.

The hypothesis that the percentage of students who show high-level configurations is significantly lower than those with low-level configurations is not confirmed for items 2 and 4 . In the other cases, this difference is significant. This may be explained in terms of the complexity of the objects and processes required to solve the VSR tasks included in the evaluation instrument.

It has been shown that the level of a configuration does not determine its effectiveness. However, by comparing skill levels to effectiveness, it becomes evident that the use of visual elements makes solving the task much easier. The students are not acquainted with moving dynamic images and maintaining the visual and positional features (visual memory skill), which in the cases of configurations with mental support only is the reason for not achieving $100 \%$ effectiveness. This means that, from an institutional point of view, configurations may or may not be effective in helping to solve the task. However, from a cognitive point of view, there are configurations with $0 \%$ effectiveness that are epistemically correct in that sense.

Finally, from an educational perspective our research has revealed the important deficiencies of teacher-training students regarding the common and in the mathematical horizon knowledge on the specific content of visualization and spatial reasoning. This then leads to the need to design, implement and assess specific training actions to foster improvement in such knowledge. Most of the activities they have performed in the subjects related to geometry 
focus on the calculation of volumes and areas as shown a number of researches, see for example Guillén, González and García (2009) in relation to our context. The almost non-existent practice in tasks of truncation, counting, rotation, cuts of figures and flat developments in instruction programs could be an explanatory factor for students' difficulties in solving spatial tasks. The boom of STEAM education might be an opportunity to incorporate these types of tasks in real-life situations. Although first of all, in the spirit of promoting solutions, it is important that future teachers become aware of the importance of visualization as an effective way to promote student achievement (Gutiérrez, 2018; Young, Levine, \& Mix, 2018).

\section{Acknowledgements}

This work was funded by the Spanish FEDER/ Ministry of Science, Innovation and Universities - Research Agency / project EDU2017_84979-R, and the European Erasmus + program (2019-1-CZ01-KA201-061377).

\section{Disclosure Statement}

No potential conflict of interest was reported by the authors.

\section{REFERENCES}

[1] Battista, M. T. (2007). The development of geometric and spatial thinking. In F. Lester, (Ed.), Second Handbook of Research on Mathematics Teaching and Learning (pp. 843908). Charlotte, NC: Information Age Publishing.

[2] Battista, M. T., \& Clements, D. H. (1998). Student's spatial structuring of 2D arrays of squares. Journal for Research in Mathematics Education, 29(5), 503-532.

[3] Benedicto, C., Acosta, C., Gutiérrez, A., Hoyos, E.A., Jaime, A. (2015). Improvement of gifted students' visualization abilities in a $3 \mathrm{~d}$ computer environment. In N. Amado, \& S. Carreira (Eds.), Proceedings of the 12th International Conference on Technology in Mathematics Teaching (pp. 363-370). Faro, Portugal: Universidad del Algarve.

[4] Blanco, T. F. (2013, September). La investigación en visualización y razonamiento espacial. Pasado, presente y futuro [Research on visualization and spatial reasoning. Past, present and future]. In A. Berciano, G. Gutiérrez, A. Estepa, \& N. Climent (Eds.), Investigación en Educación Matemática XVII (pp. 19-42). Leioa, Bizkaia: UPV.

[5] Blanco, T. F. (2011). Una aproximación ontosemiótica a la visualización y el razonamiento espacial. (Doctoral dissertation). Retrieved from https://minerva.usc.es/xmlui/ handle/10347/3692

[6] Blanco, T. F., Godino J. D., \& Cajaraville, J. A. (2012).
Razonamiento geométrico y visualización espacial desde el punto de vista ontosemiótico [An Onto-Semiotic Approach to Geometrical Reasoning and Spatial Visualization]. Bolema, Rio Claro (SP), 26(42A), 39-63.

[7] Blanco, T. F., Diego-Mantecón, J. M., Sequeiros, P. G. (2018). Truncamiento de los vértices de un cubo. UNO: Revista de didáctica de las matemáticas, 80(2), 27-34.

[8] Blanco, T. F., Diego-Mantecón, J. M., Sequeiros, P. G. (2019). Procesos de Visualización en una Tarea de Generación y Representación de Cuerpos de Revolución. Bolema: Boletim de Educação Matemática, 33(64), 768-789.

[9] Blanco, T. F., Sequeiros, P. G., Núñez, C., \& Salgado, M. (2017, February). A scale on cognitive configurations for tasks requiring visualization and spatial reasoning. In $\mathrm{T}$. Dooley, \& G. Gueudet (Eds.), Proceedings of the Tenth Congress of the European Society for Research in Mathematics Education (CERME10) (pp. 687-688). Dublin, Ireland: DCU Institute of Education and ERME.

[10] Buckley, J., Seery, N., \& Canty, D. (2019). Investigating the use of spatial reasoning strategies in geometric problem solving. International Journal of Technology and Design Education, 29(2), 341-362.

[11] Clements, M. (2014). Fifty Years of Thinking About Visualization and Visualizing in Mathematics Education: A Historical Overview. In M. N. Fried, \& T. Dreyfus (Ed.), Mathematics \& Mathematics Education: Searching for Common Ground (pp. 177-192). Dordrecht: Springer.

[12] Cohen, N. (2003, July). Curved solid nets. In N. Pateman, B. J. Dourgherty, \& J. Zillox (Eds.), Proceedings of the 27th PME International Conference, 2 (pp. 229-236). Honolulu, HI: Center for Research and Development Group, University of Hawaii.

[13] Cosío, J. (1997). Diagnosis de la habilidad de visualizar en el espacio 3D con estudiantes de Bachillerato del Bilbao metropolitano. (Doctoral dissertation). Lejona, Spain: Servicio Editorial de la Universidad del País Vasco.

[14] Cunningham, S. (1991). The visualization environment for mathematics education. In W. Zimmermann, \& S. Cunningham (Eds.), Visualization in Teaching and Learning Mathematics, 19 (pp. 67-76). Washington, DC, USA: Mathematical Association of America.

[15] Del Grande, J. J. (1987). Spatial perception and primary geometry. In M. Montgomery, \& A. Shulte (Eds.), Learning and Teaching geometry, K-12 (pp. 126-135). Reston, VA: National Council of Teachers of Mathematics.

[16] Duval, R. (1999, October). Representation, vision and visualization: cognitive functions in mathematical thinking. In F. Hitt, \& M. Santos (Eds.), Proceedings of the 21st Annual Meeting North American Chapter of the International Group of PME (pp. 3-26). Cuernavaca, Morelos, Mexico: PME-NA.

[17] Font, V., Godino, J. D., \& Gallardo, J. (2013). The emergence of objects from mathematical practices. Educational Studies in Mathematics, 82, 97-124.

[18] Gaulin, C. (1985). The need for emphasizing various graphical representations of 3-dimensional shapes and relations. Proceedings of the 9th PME International 
Conference, 2 (pp. 53-71). Noordwijkehout: OW \& OC, State University of Utrecht.

[19] Godino, J. D., Batanero, C., \& Font, V. (2007). The onto-semiotic approach to research in mathematics education. ZDM-The International Journal on Mathematics Education, 39(1-2), 127-135.

[20] Godino, J. D., Blanco, T. F., Gonzato, M., \& Wilhelmi, M. (2013, February). Synergy between visual and analytical languages in mathematical thinking. In B. Ubuz, C. Haser, \& M. A. Mariotti (Eds.), Proceedings of the Eighth Congress of the European Society for Research in Mathematics Education (CERME 8), (pp. 645-654). Ankara, Turkey: Middle East Technical University and ERME.

[21] Godino, J.D., Cajaraville, J. A., Blanco, T. F., \& Gonzato, M. (2012). Una aproximación ontosemiótica a la visualización en educación matemática [An onto-semiotic approach to visualization in mathematics education]. Enseñanza de las Ciencias, 30(2), 163-184.

[22] Godino, J. D., Font, V., Wilhelmi, M. R., \& Lurduy, O. (2011). Why is the learning of elementary arithmetic concepts difficult? Semiotic tools for understanding the nature of mathematical objects. Educational Studies in Mathematics, 77(2), 247-265.

[23] Godino, J. D., Gonzato, M., Contreras, Á., Estepa, A., \& Díaz-Batanero, C. (2016). Evaluación de Conocimientos Didáctico-Matemáticos sobre Visualización de Objetos Tridimensionales en Futuros Profesores de Educación Primaria [Assessing Didactic-Mathematical Knowledge of Prospective Primary School Teachers on Visualization of Three-Dimensional Objects]. REDIMAT, 5(3), 235-262.

[24] Godino, J.D., \& Burgos, M. (2017, September). Perspectiva ontosemiótica del razonamiento algebraico escolar [Onto-semiotic perspective of the school algebraic reasoning]. In J. M. Muñoz-Escolano, A. Arnal-Bailera, P. Beltrán-Pellicer, M. L. Callejo, \& J. Carrillo (Eds.), Investigación en Educación Matemática XXI (pp. 49-66). Zaragoza: SEIEM.

[25] Gonzato M. (2014). Evaluación de conocimientos de futuros profesores de educación primaria para la enseñanza de la visualización espacial. (Doctoral dissertation). Retrieved from https://www.ugr.es/ jgodino/Tesis_doctorales/Margh erita_Gonzato_tesis.pdf

[26] Gonzato, M., Blanco, T.F., \& Godino, J.D. (2011). Tareas para el desarrollo de habilidades de visualización y orientación espacial: un estudio sistemático basado en la investigación didáctica. Números, 77, 99-117.

[27] Gorgorió, N. (1998). Exploring the functionality of visual and non-visual strategies in solving rotation problems. Educational Studies in Mathematics, 35, 207-231.

[28] Guillén, G. (2005). Análisis de la clasificación. Una propuesta para abordar la clasificación en el mundo de los sólidos. Educación Matemática, 17(2), 117-152.

[29] Guillén, G., González, E., García, M. A. (2009). Criterios específicos para analizar la geometría en libros de texto para la enseñanza primaria y secundaria obligatoria. Análisis desde los cuerpos de revolución. In M. J. González, M. T. González, \& J. Murillo (Eds.), Investigación en Educación Matemática XIII (pp. 247-258). Santander: SEIEM.
[30] Gutiérrez, A. (2018). Visualization in school mathematics analyzed from two points of view. In K. S. Mix, \& M. T. Battista (Eds.), Visualizing mathematics. The role of spatial reasoning in mathematical thought (pp. 165-169). Cham, Switzerland: Springer.

[31] Gutiérrez, A. (1998). Las representaciones planas de cuerpos 3-dimensionales en la enseñanza de la geometría especial. EMA, 3(3), 193-220.

[32] Gutiérrez, A. (1996, July). Visualization in 3-dimensional geometry: In search of a framework. In L. Puig, \& A. Gutierrez (Eds.), Proceedings of the 20th PME International Conference, 1, (pp. 3-19). Valencia: PME.

[33] Hershkowitz, R. (1989). Visualization in geometry: Two sides of the coin. Focus on Learning Problems in Mathematics, 11(1), 61-76.

[34] Hill, H. C., Ball, D. L., \& Schilling, S. G. (2008). Unpacking pedagogical content knowledge: Conceptualizing and measuring teachers' topic-specific knowledge of students. Journal for Research in Mathematics Education, 39, 372 400 .

[35] Krutetskii, V. A. (1976). The psychology of mathematical abilities in schoolchildren. Chicago: The University of Chicago Press.

[36] Lubinski, D. (2010). Spatial ability and STEM: A sleeping giant for talent identification and development. Personality and Individual Differences, 49 (4), 344-351.

[37] Malara, N. (1998, July). On the difficulties of visualization and representation of $3 \mathrm{D}$ objects in middle school teachers. In A. Olivier, \& K. Newstead (Eds.), Proceedings of the 22nd PME International Conference, 3 (pp. 239-246). Stellenbosch, South Africa: PME.

[38] Mesquita, A. L. (1992). The types of apprehension in spatial geometry: sketch of a research. Structural topology, 18, 1930 .

[39] Miragliotta, E., \& Baccaglini-Frank, A. (2017, February). Visuo-spatial abilities and Geometry: A first proposal of a theoretical framework for interpreting processes of visualization. In T. Dooley, G. Gueudet (Eds.), Proceedings of the Tenth Congress of the European Society for Research in Mathematics Education (CERME10) (pp. 3952-3958). Dublin, Ireland: DCU Institute of Education and ERME.

[40] Mix, K. S., \& Battista, M. T. (Eds.) (2018). Visualizing Mathematics: The Role of Spatial Reasoning in Mathematical Thought. Cham, Switzerland: Springer.

[41] Nemirovsky, R., \& Noble, T. (1997). On mathematical visualization and the place where we live. Educational Studies in Mathematics, 33(2), 99-131.

[42] Parzysz, B. (1988). "Knowing" vs "seeing": Problems of the plane representation of space geometry figures. Educational Studies in Mathematics, 19(1), 79-92.

[43] Pittalis, M., \& Christou, C. (2010). Types of reasoning in 3D geometry thinking and their relation with spatial ability. Educational Studies in Mathematics, 75(2), 191-212.

[44] Pitta-Pantazi, D., \& Christou, C. (2009). Cognitive styles, dynamic geometry and measurement performance. Educational Studies in Mathematics, 70, 5-26. 
[45] Phillips, L. M., Norris, S.P., \& Macnab, J.S. (2010). Visualization in mathematics, reading and science education. Dordrecht, The Netherlands: Springer.

[46] Presmeg, N. C. (2006). Research on visualization in learning and teaching mathematics. In A. Gutiérrez, \& P. Boero (Eds.), Handbook of research on the psychology of mathematics education: Past, present and future (pp. 205-235). Rotterdam, The Netherlands: Sense Publishers.

[47] Presmeg, N. C. (1986). Visualization and mathematical giftedness. Educational Studies in Mathematics, 17, 297311.

[48] Presmeg, N. C. (2008, July). An overarching theory for research in visualization in mathematics education. Plenary paper presented at Topic Study Group 20, Visualization in the teaching and learning of mathematics, 11 th International Congress on Mathematics Education (ICME-11), Monterrey, Mexico.

[49] Rabab'h, B., \& Veloo, A. (2015). Spatial visualization as mediating between mathematics learning strategy and mathematics achievement among 8th grade students. International Education Studies, 8(5), 1-11.

[50] Rafi, A., Anuar, K., Samad, A., Hayati, M., \& Mahadzir, M. (2005). Improving spatial ability using a web-based virtual environment. Automation in Construction, 14, 707-715.

[51] Ramírez, R., \& Flores, P. (2017). Habilidades de visualización de estudiantes con talento matemático: Comparativa entre los test psicométricos y las habilidades de visualización manifestadas en tareas geométricas. Enseñanza de las Ciencias, 35, 79-196.

[52] Rivera, F. (2011). Toward a visually-oriented school mathematics curriculum: Research, theory, practice, and issues. The Netherlands: Springer.

[53] Saads, S., \& Davis, G. (1997). Spatial Abilities, van Hiele levels \& language use in three dimensional geometry. In E. Pehkonen (Ed.), Proceedings of the 21th PME International Conference, 4 (pp. 104-111). Lahti, Finland: PME.

[54] Son, J-W. (2006). Investigating preservice teachers' understanding and strategies on a student's errors of reflective symmetry. In J. Navotna, H. Moraova, M. Kratna, \& N. Stehlikova (Eds.), Proceedings of the 30th Annual Meeting of the International Group for the Psychology of Mathematics Education, 5 (pp. 145-152). Prague, Czech Republic: PME.

[55] Tatsis, K., \& Moutsios-Rentzos, A. (2013, July). Pre-service teachers describe geometrical figures: The 'broken phone' revisited. In A. M. Lindmeier, A. Heinze (Eds.), Proceedings of the 37th Conference of the International Group for the Psychology of Mathematics Education, 4 (pp. 265-272). Kiel, Germany: PME.

[56] Verdine, B. N., Golinkoff, R. M., Hirsh-Pasek, K., \& Newcombe, N. S. (2014). Finding the missing piece: Blocks, puzzles, and shapes fuel school readiness. Trends in Neuroscience and Education, 3(1), 7-13.

[57] Yenilmez, K., \& Kakmaci, O. (2015). Investigation of the Relationship between the Spatial Visualization Success and Visual/Spatial Intelligence Capabilities of Sixth Grade Students. International Journal of Instruction, 8(1), 189 204.
[58] Young, C., Levine, S. C., and Mix, K. S. (2018). What Processes Underlie the Relation Between Spatial Skill and Mathematics? In K. S. Mix, \& M. T. Battista (Eds.), Visualizing mathematics. The role of spatial reasoning in mathematical thought (pp. 117-148). Cham, Switzerland: Springer. 